\title{
ENSAIANDO O "NOVO" EM EDUCAÇÃO FÍSICA ESCOLAR: A PERSPECTIVA DE SEUS ATORES
}

\author{
DR. PAULO EVALDO FENSTERSEIFER \\ Doutor em Educação pela Unicamp. Professor adjunto do Departamento de \\ Pedagogia da Universidade Regional do Noroeste do Estado do Rio \\ Grande do Sul - Unijuí (Rio Grande do Sul - Brasil) \\ e-mail: fenster@unijui.edu.br

\begin{abstract}
MS. MARLON ANDRÉ DA SILVA
Mestre em Educação nas Ciências pela Unijuí. Professor do Instituto Federal de Educação Rio Grande do Sul - Campus Canoas (Rio Grande do Sul - Brasil)

e-mail:marlon.silva@canoas.ifrs.edu.br
\end{abstract}

\begin{abstract}
RESUMO
Este artigo resulta de pesquisa com professores que realizam práticas pedagógicas "inovadoras" na Educação Física escolar. Procura-se conhecer e analisar os elementos que, na ótica desses professores, foram/estão sendo importantes para a realização e sustentação dessas práticas. Os relatos dos professores investigados e a posterior análise dos elementos por eles apontados, por um lado, reforçam a ideia de que a compreensão da totalidade desse fenômeno não pode ser efetuada sem olharmos para a complexa rede de relações de fatores intra e extraescolares. Por outro, tampouco é possível abordar o problema sem levar em consideração o percurso profissional do professor "inovador".
\end{abstract}

PALAVRAS-CHAVE: Prática pedagógica; formação profissional; educação física escolar; escola. 
Entendemos que a área de Educação Física (EF) escolar vive uma espécie de transição no tocante a sua prática pedagógica. Tal transição poderia ser caracterizada como um movimento de aproximação dessa área com os propósitos da escola, ou seja, a Educação Física escolar estaria buscando elementos para construir uma prática pedagógica não mais centrada no exercitar-se, mas na aquisição de novos conhecimentos relacionados às manifestações da Cultura Corporal de Movimento. Em outras palavras, como componente curricular seria papel da Educação Física problematizar prática e teoricamente a cultura corporal de movimento. Práticas pedagógicas que ousam materializar essa referida concepção de EF são entendidas, neste estudo, como práticas "bem sucedidas" ou "inovadoras".

Os extremos dessa transição, a saber: o desinvestimento pedagógico' e as práticas pedagógicas inovadoras têm motivado estudos no interior da área. Mais especificamente, ocupam-se estes estudos em investigar e compreender os fatores implicados na constituição tanto de um como de outro fenômeno.

Tem-se percebido que o desempenho profissional vincula-se fortemente ao contexto específico das práticas pedagógicas. Nas palavras de Fensterseifer e González (2008, p. I):

Estes espaços parecem constituir-se em 'Rodas Vivas' que consomem as 'boas intenções' gestadas nos espaços de formação ou presentes nas políticas educacionais dos mais diversos governos. Este poder corrosivo parece mover-se por inércia e nada deixar a salvo, no entanto, sabemos que no interior dos espaços educacionais emergem propostas pedagógicas diferenciadas, as quais também parecem não obedecer a lógicas lineares, motivadas por razões que muitas vezes nos escapam.

Nesse sentido, o presente artigo pretende contribuir com as reflexões da área sobre como se dá a mudança da prática pedagógica em EF e que elementos podem ser considerados significativos nesse processo. Acreditamos que, com essa escolha, por um lado, ao contemplar práticas "inovadoras", rompemos com a postura denuncista, que se limita a apontar culpados, ou conformista, que se limita a justificar o imobilismo, com o cuidado de não promover idealizações simplificadoras. Por outro lado, não buscamos a "novidade" nas propostas oficiais oriundas de políticas

I. "Desinvestimento pedagógico" ou "abandono do trabalho docente" são termos usados para se referir àqueles professores que "abrem mão de seu compromisso ético, político, pedagógicoprofissional de ensinar, porém continuam no emprego, imobilizados ou por falta de opção ou por certo conformismo vinculado a sua estratégia de sobrevivência no sistema" (SANTINI; MOLINA NETO, 2005, p. 212). 
públicas que, pelo seu caráter de abrangência, possuem características genéricas, o mesmo ocorrendo com obras de referência produzidas no âmbito acadêmico.

Optamos por realizar nossa investigação tomando em conta o trabalho realizado, com suas devidas justificações, por professores de EF em contextos específicos. Opção que impede generalizações, porém evidencia com maior profundidade a intergenese de uma compreensão de EF com seus desdobramentos no plano da intervenção.

Para a consecução desse propósito, e concordando que é preciso considerar a "roda viva" da Educação Física escolar, realizamos uma pesquisa que se propôs a "dar voz" a professores que tentam e conseguem tratar a Educação Física como um componente curricular articulado com o projeto político-pedagógico da escola. Por essa perspectiva, ou seja, a de valorizar as chamadas microestruturas e ouvir o que os docentes têm a dizer, este estudo se orientou pelos princípios da investigação qualitativa, consistindo metodologicamente num conjunto de estudos de caso desenvolvido com três professores de Educação Física (sujeitos-participantes), tendo como instrumentos de coleta de evidências a técnica do grupo focal e entrevistas abertas com os professores, sujeitos desta pesquisa.

A escolha dos casos contou com a colaboração de professores da universidade local (Unijuí), com a posição dos gestores das escolas em que atuam os professores, e, por fim, com a aproximação ao campo buscando a confirmação ou não dos indicadores. Esta aproximação no decorrer do estudo também nos permitiu verificar a consistência das declarações obtidas nos instrumentos de pesquisa. Cabe destacar que as interpretações foram construídas no diálogo imediato ou corroboradas a posteriori por ocasião de novos encontros.

A proposição de ouvir os professores que realizam uma prática pedagógica considerada inovadora em Educação Física, com vistas a conhecer alguns elementos que, na sua ótica, contribuem na realização dessas práticas, é perpassada pela concepção apontada por Betti (2005), de que a compreensão dos fenômenos da área deve ser buscada dentro dela mesma. Nesse sentido, a escuta dos professores se deu com o objetivo de saber onde buscaram/buscam inspiração, saberes e fazeres de aprendizagem para pensar e sustentar estas práticas pedagógicas.

Foram determinantes para esta escolha dos casos a presença de características que, dada a tradição da área, julgamos permitir a identificação de uma experiência "inovadora", tais como: a) proposta pedagógica articulada com o currículo da escola; b) desenvolvimento de conteúdos de forma progressiva e com preocupação sistematizadora; c) envolvimento do conjunto dos(as) alunos(as) nas aulas; d) a presença de conteúdos variados representativos da diversidade que compõe a cultura corporal de movimento; e) processos de avaliação articulados com os objetivos do 
componente curricular. Enfim são características que podem não estar presentes em sua totalidade, mas denotam o movimento no sentido de evidenciar a ruptura com a noção de EF como "atividade" para a condição de "disciplina". Movimento que assume um caráter inovador na especificidade da tradição deste componente e que também deve levar em conta os contextos em que se desenvolve, o que significa afirmar que algo pode ser inovador em determinado contexto e não em outro.

Entendemos que o conhecimento e uma melhor compreensão desses elementos podem ajudar a área a potencializar a tradução das propostas pedagógicas críticas $^{2}$ que vêm sendo elaboradas em ações concretas nas escolas. Para esse intento tomamos as falas dos professores como referenciais para refletir sobre a prática pedagógica, acreditando que elas desvelam percepções e concepções com as quais e a partir das quais podemos dialogar sobre as possibilidades desta "nova" perspectiva na EF escolar.

\section{OS ENTREVISTADOS E SUA TRAJETÓRIA DE FORMAÇÃO INICIAL E CONTINUADA}

Faz-se necessário esclarecer que todos os professores sujeitos desta pesquisa realizaram o curso de graduação em Educação Física na mesma universidade ${ }^{3}$, ou seja, todos tiveram um percurso semelhante no que diz respeito a disciplinas e oportunidades de participação em projetos do curso, bem como tiveram acesso aos mesmos professores - guardadas algumas exceções. É importante ressaltar que a gênese do curso de Educação Física desta universidade se deu num momento ímpar da história da Educação Física no Brasil: quando se discutiam fortemente (em tom de denúncia) os propósitos do tecnicismo na Educação Física e suas finalidades sociais, assim como da Educação. Na formatação do referido curso, segundo relatam seus professores, foram ouvidos pesquisadores que se vinculavam ao movimento renovador vivenciado pela da EF brasileira nas décadas de 70 e 80 do século passado e que se dispuseram a contribuir. $\bigcirc$ propósito básico era constituir um curso de graduação em Educação Física que materializasse os anseios dos pesquisadores da época em relação a uma perspectiva crítica para a área. Algo como "formar profissionais capazes de tirar a EF de sua crise".

Talvez seja esse um dos motivos que fez com que o curso de Educação Física dessa universidade privilegiasse espaços em seu programa curricular para disciplinas

2. Sempre que vincular aqui a ideia de crítica tomamos emprestada a concepção de Betti (2003) para o qual esta é entendida como "o exame racional (tendo em vista algum juízo de valor) dos critérios, quer dizer, dos princípios fundantes das diversas práticas da cultura", neste caso relacionada à Educação e à Educação Física.

3. Universidade Regional do Noroeste do Estado do Rio Grande do Sul - Unijú́. 
com fundamentação científica e filosófico-humanista. Esse fato é destacado pelos professores entrevistados como um dos elementos constitutivos de práticas pedagógicas "inovadoras" na Educação Física escolar.

Acredito que o fato de o curso estar vinculado à pedagogia ${ }^{4}$, de ter um lado humanista, foi o diferencial que mexeu conosco, de fazer nós entendermos que vamos trabalhar com um aluno que também está cheio de ideias, que tem seus desejos, suas dificuldades..., e que está ali para aprender e nós temos que achar um vínculo para ensinar algo que consideramos importante para ele. (Professor B).

Outro elemento ligado à formação inicial, apontado pelos professores como provável constituidor de suas práticas, é a participação em projetos (oficinas) oferecidos pelo curso de Educação Física junto à comunidade local, concomitante com a realização do curso de graduação (por exemplo, o AABB Comunidade ${ }^{5}$ ). Durante a reunião no estilo grupo focal e, posteriormente, nas entrevistas particulares, várias vezes este fato foi lembrado como algo extremamente positivo para a formação profissional, ressaltando-se o seu caráter filosófico-humanista, ou seja, afirmando que esses projetos eram norteados por uma visão questionadora acerca dos problemas da sociedade como um todo e da educação em especial.

fato, entretanto, de o curso de graduação em Educação Física desses professores ter valorizado disciplinas de cunho científico e filosófico não pode, no nosso entendimento, ser tomado como único motivador de práticas pedagógicas inovadoras. Como postula Bracht (2005, p. 4I), apoiado em Perrenoud ( 1993):

A formação do educador é um contínuo bem mais abrangente que o momento de sua formação inicial. A trajetória singular do indivíduo, sua história de vida se amalgama com as marcas de sua formação inicial e de sua formação continuada. Por essa razão, a formação inicial não pode responder por todas as limitações da formação do professor, nem ser um deus que, de forma miraculosa, supere os limites do sistema de ensino. É preciso ter cautela para não dimensionar excessivamente o lugar da formação inicial na constituição do docente.

Nessa perspectiva, entendemos que a formação inicial dos professores aqui estudados, por privilegiar a construção de um pensamento reflexivo sobre a

4. A referida universidade organiza-se em Departamentos que comportam um ou mais programas de graduação e pós-graduação. Dentro desta estrutura o curso de Educação Física está alocado no Departamento de Pedagogia.

5. O referido programa garante o atendimento a 280 crianças entre 7 e 17 anos, em situação de vulnerabilidade social, tendo como objetivo o combate à evasão e à repetência escolar. É uma parceria entre a Associação Atlética Banco do Brasil, prefeitura local e a Unijuí, esta responsável pelo trabalho pedagógico. 
prática pedagógica, tem contribuído para que esses professores possam enfrentar a tradição pedagógica da área. Porém, não é possível considerar tal evento como uma situação determinante de práticas inovadoras, pois sabemos que outros alunos também passaram pelo mesmo processo de formaçãa e, atualmente, não realizam práticas pedagógicas "inovadoras”. Evidencia-se que a formação inicial dos professores pesquisados contemplou pontos de experimentação da prática pedagógica, como nos casos dos projetos e oficinas junto à comunidade. $O$ aspecto contempla a preocupação de Nóvoa (1995, p. 28), segundo o qual é importante que:

a formação passe pela experimentação, pela inovação, pelo ensaio de novos modos de trabalho pedagógico, e por uma reflexão crítica sobre sua utilização. A formação passa por processos de investigação, diretamente articulados com as práticas educativas. Neste sentido, a dinamização de dispositivos de investigação-ação e de investigação-formação pode dar corpo à apropriação pelos professores dos saberes que são chamados a mobilizar no exercício da sua profissão. $\bigcirc$ esforço de formação passa sempre pela mobilização de vários tipos de saberes: saberes de uma prática reflexiva; saberes de uma teoria especializada; saberes de uma militância pedagógica.

A formação do professor é um ato contínuo, não termina ao concluir a graduação ou qualquer outra etapa de seu processo formativo; estende-se, na literal acepção do termo "processo", por toda sua trajetória profissional, que é, portanto, singular. Os relatos abaixo permitem uma ideia da diversidade de conflitos por que passam os professores de Educação Física que se empenham com a melhoria de sua profissão.

Muitos dos meus [alunos] lá só estão na escola porque é obrigatório. Não fosse, muitos estariam trabalhando, daí surge a revolta deles: por que tem que estar lá? Então eles não vêem importância de estar lá. (Professor C).

Bom, uma dificuldade quando eu entrei no universo do trabalho é o planejamento ; não tava planejando, não tinha um planejamento contínuo de tema; trabalhava de forma esporádica, com alguns temas, por exemplo, com voleibol, com handebol, com futsal, com basquete eu não trabalhei nessa escola do interior, trabalhei com ginástica também, só que se limitava a isso e não conseguia sair; teve uma época que machuquei o joelho e daí fiquei sentado e joguei a bola, não adianta, a gente passa por esse momento, a gente critica na formação inicial e é envolvido por essa roda viva na escola. (Professor A).

6. Neste depoimento evidencia-se que embora haja reconhecimento do papel positivo da formação inicial, este reconhecimento não significa que não haja críticas a esta formação. Uma delas vincula-se às dificuldades de um planejamento curricular de longo prazo. 
Outra dificuldade que percebo é a questão de o professor ter que buscar mais, em termos de materiais, de trocas com outros professores. Sistematizar mais. Por exemplo, este ano eu trabalhei com o judô, como é que eu fiz então: primeiro trabalhei com eles o que eles sabiam do judô, partindo do que eles sabiam a gente vivenciou um pouco do judô, depois eu falei das regras oficiais do judô, das faixas do judô, mostrei fitas, vídeos, e para sistematizar solicitei um trabalho, que deveria ter uma capa com desenho, porque era sexta série. Mas as vezes eu fico pensando: será que somente isso que eu fiz foi suficiente para eles terem apreendido? (Professor B).

Esses conflitos são comuns à maioria dos professores que se interessam em aperfeiçoar sua prática; e sua resolução passa pela busca de alternativas que contemplem subsídios teórico-metodológicos para melhorar a prática pedagógica. Nessa busca, o caminho mais comum tem sido a opção por cursos de pós-graduação. Os testemunhos dos professores sujeitos desta pesquisa apontam para a formação continuada como um dos principais elementos que favorecem a qualificação da prática pedagógica do professor. Contudo, sabemos que a formação continuada nos moldes tradicionais tem sido alvo de inúmeras críticas: Tardif (2002), Sacristán (1999), Perrenoud (2002), Imbernón (2006), Nóvoa (1999); e na Educação Física: Bracht (2005), Betti (2005), entre outros.

Especificamente no caso da Educação Física escolar não se tem conseguido grandes avanços no sentido de aproximar sua prática pedagógica dos propósitos da instituição escolar, cabe discutir as alternativas atualmente estudadas para enfrentar essa situação.

Em se tratando da formação continuada, Bracht (2005) entende que esta não somente deve ser intensificada como também repensada a sua atual formatação. Baseado em um estudo/diagnóstico, o referido autor também defende outras alternativas: "Existem indicadores que a tradicional forma de capacitação docente via cursos, seja de caráter extensionista de 40, 60 ou 80 horas/aula, seja os de pósgraduação, baseados na perspectiva da transmissão do saber, tem pouca efetividade" (BRACHT, 2005, p. 130). Afirma o autor que a formação continuada "precisa assumir efetivamente caráter permanente e a sua forma privilegiar a ideia da formação de um professor crítico-reflexivo" (BRACHT, 2005, p. 130).

Para Sacristán (1999), a necessidade de repensar os programas tradicionais de formação de professores deve privilegiar também as dimensões pessoais e culturais e não somente os aspectos técnicos da profissão. Tal afirmação leva em consideração o atual estágio social da profissão docente comparativamente a outras. Não é possível tratar de aspectos apenas técnicos na profissão docente como se as condições psicológicas e culturais do professor fossem alheias a ela. "Educar e ensinar é, sobretudo, permitir um contacto com a cultura, na acepção mais geral do 
termo; trata-se de um processo em que a própria experiência cultural do professor é determinante" (SACRISTÁN, 1999, p. 67).

No caso da Educação Física, pensamos que estudos acadêmicos, de caráter teórico ou prático, são válidos à medida que oferecem subsídios para que o professor possa refletir sobre sua prática e fundamentá-la teoricamente, contribuindo, dessa forma, para que consiga justificar e/ou defender suas ações pedagógicas frente à comunidade escolar.

No texto Sobre teoria e prática: manifesto pela redescoberta da educação física, Betti (2005) considera que a atual situação problemática da Educação Física não está na falta de teoria, mas na relação teoria-prática. Segundo o autor, "a perda de vínculos da pesquisa científica e da teoria com a vida viva da EF faz com que as relações teoria-prática permaneçam como o problema principal na EF" (BETTI, 2005, p. I) Para o autor, está claro que o avanço teórico que se obteve na EF brasileira não se converteu em melhores práticas na EF escolar. Esta relação entre teoria e prática no fazer docente em Educação Física pode ser considerada em diferentes perspectivas: tradicional-técnica; legitimadora e/ou crítica, e reflexiva.

Pela perspectiva tradicional-técnica se entende que pesquisa científica produz abstrações e generalizações a partir da prática - ou seja, teorias - as quais se pretende sejam aplicáveis de modo direto a todos os contextos da prática. Tende-se, assim, a não considerar os aspectos particulares do ambiente escolar concreto. Em síntese, de acordo com Betti (2005), "embora exista uma referência inicial à prática, a relação teoria-prática finda por dar-se em "mão única”, sem qualquer mediação, fluindo da teoria para a prática".

Com a perspectiva crítica tem ocorrido um distanciamento da teoria em relação à prática. Tal distanciamento ocorre devido à busca de apoio conceitual em disciplinas fora da área da educação, como a psicologia, a sociologia, a história etc., como se a própria educação não desse conta desse desenvolvimento. "Em decorrência, os princípios educativos passaram a ser justificados independentemente das práticas educativas (pelo recurso aos conhecimentos psicológicos, sociológicos etc.) e estas, por sua vez, se distanciaram das teorias" (BETTI, 2005, p. I). Entende-se, nesse sentido, que o mais importante passa a ser o embate entre as diferentes teorias, as quais, por sua vez, como em um círculo vicioso necessitam de outras teorias para se justificar. Logo, teorias levam a teorias. Nessa dinâmica, a relação inicial com a prática se esvaece.

Já a relação entre a teoria e a prática existente na perspectiva reflexiva ${ }^{7}$ considera que o mais importante nas pesquisas em educação é a busca pela reconstrução

7. Não objetivamos neste artigo problematizar as noções de "critica" e de "reflexivo". Reconhecemos a polissemia destes termos, por isso indicamos a quem interessar um maior aprofundamento a obra de Pimenta e Ghedin 2002. Nosso interesse aqui é reconhecer a necessidade de aprofundar as relações teoria/prática como modo de enfrentar o descompasso entre as chamadas "soluções teóricas" e as "mudanças práticas". 
e transformação da prática. Na concepção de Betti (2005, p. I), "tratar-se-ia de uma pesquisa realizada no interior do empreendimento educativo, e que pudesse contribuir para o seu enriquecimento". Acrescenta este autor, baseado em Elliott (1993), que "a pesquisa não deve separar-se da prática; a prática mesma é a forma de investigação, pois nessa situação desconhecida são levantadas hipóteses para além da atual compreensão do professor" (BETTI, 2005, p. I). Contrariando as perspectivas anteriores, a reflexão nesta perspectiva tem como alvo a própria prática (reflexão sobre a ação).

Nesse sentido, a produção teórica deriva das tentativas de mudar as práticas, e estas são o meio pelo qual se elaboram e comprovam as suas próprias teorias, ou seja, as práticas constituem-se em categorias de hipóteses a comprovar. A teoria adquire um sentido de unidade com a prática, não no sentido estático de dar explicações às questões práticas, mas no sentido dinâmico de auxiliar o encaminhamento, a direção refletida, crítica e criativa da situação. A teoria é vista como reveladora de várias alternativas e, pela análise e diálogo com a situação, contribui para fazer avançar o conhecimento sobre a validade de cada uma delas, e assim são geradas relações de interrogações mútuas entre a teoria e a prática, em decorrência do que ambas se transformam (BETTI, 2005, p. I).

Parece-me que a compreensão de como tais perspectivas permeiam as pesquisas em educação pode contribuir nas reflexões sobre as dificuldades que as próprias pesquisas em educação apresentam. No contexto das duas primeiras perspectivas, é perfeitamente possível que o pesquisador seja reconhecido como aquele sujeito que "estuda" acerca de como os professores da escola devem trabalhar. Dessa maneira, é compreensível que os professores da escola básica construam um imaginário segundo o qual esse pesquisador não é bem vindo, sendo reconhecido como alguém que somente aparece para criticar, ou para dizer como eles devem trabalhar.

As lacunas existentes entre o ensino e a pesquisa exigem de seus atores uma aproximação: "sujeito-pesquisador" e "sujeito-pesquisado"; também uma aproximação entre teoria e prática, entre pesquisa e ensino. Tais aproximações parecem encontrar espaço em algumas metodologias que, mesmo precária e timidamente, surgem como alternativas para quem se coloca na perspectiva reflexiva acima aludida: é o caso da pesquisa de tipo etnográfico e, principalmente, da pesquisa-ação. Como sublinha Betti (2005, p. I), "é possibilidade para quem deseja redescobrir a Educação Física escolar em seu contexto vivo, onde professores e alunos compartilham uma experiência humana."

Apesar de os professores sujeitos desta pesquisa manifestarem concordância com as críticas à formação continuada na perspectiva tradicional, os mesmos afirmam que um curso de especialização em Educação Física escolar realizado por eles foi 
de extrema importância para que adquirissem conhecimentos fundamentais para repensar suas práticas pedagógicas em Educação Física.

[...] eu não me acomodei, tanto que eu esperava já há algum tempo uma especialização na área da Educação Física escolar para me ajudar nesse sentido. Tanto que eu entrei na pós somente por causa da disciplina de planejamento porque eu acho que esta disciplina deveria acontecer durante os dois anos da pós. E ainda faltaria tempo para algumas coisas, porque daí tu revê conceitos, bibliografia, discute sobre citações de autores e tu sabe que a área da Educação Física é imensa, não é qualquer conteúdo de $1^{a} a 4^{a}$, não é qualquer conteúdo de $5^{a}$ a $8^{a}$ ou para o ensino médio. Então tu conseguir fazer essa seleção dentro da tua área, da tua realidade... (Professor $\mathrm{C}$ ).

Também foi importante porque foi uma pós logo depois do curso, eu estava quente com os conteúdos ainda. Foi dessa pós, através da troca com colegas e professores que surgiu nosso grupo de estudos. Também prova que pós, mestrado, doutorado me parece uma coisa lógica, que tudo mundo deveria fazer. (Professor B).

Percebe-se que a formação continuada, como ocorreu com os professores entrevistados, mesmo que desenvolvida nos moldes tradicionais, ainda pode guardar espaços de abertura por onde os sujeitos podem escapar ao tradicional e inaugurar uma nova forma de pensar seu fazer pedagógico. Nas experiências ou relatos de formação continuada dos professores entrevistados, a participação em um componente que integrou o currículo de um curso de pós-graduação ofereceu subsídios e constituiu uma oportunidade para esse exercício.

Também é destacada, pelos professores B e C, a experiência com um grupo de estudos originado durante a realização da pós-graduação e que teve a participação de um professor que passou um período na instituição ${ }^{8}$. Segundo relatos dos professores, essa participação no grupo contribuiu sensivelmente para o estudo de outras maneiras possíveis de se realizar a prática pedagógica em Educação Física. Entre os conhecimentos discutidos/adquiridos através desses encontros, consideram o planejamento participativo como dos mais importantes.

[...] a gente começou com aquele grupo de estudos, com o FDM9 , que tinha se formado junto, e feito a pós, e trabalhado na $\mathrm{AABB}$, todos juntos. E depois então o $S \mathrm{SP}^{10}$ veio, por intermédio do

8. Professor e pesquisador que, por vínculos de ordem pessoal, permaneceu em ljuí, RS, por determinado período, logo após a conclusão de seu curso de mestrado na Universidade Federal de Santa Maria.

9. FDM é professor pesquisador que desenvolve pesquisa relatando experiência própria com a prática pedagógica em Educação Física na perspectiva de componente curricular.

10. SP é o professor e pesquisador citado na nota 8. 
$F G^{11}$, veio e ficou aqui um tempo. O FG participava, às vezes o $P F^{12}$, e botaram fogo, lenha na fogueira, e a gente foi atrás. Daí eu iniciei em março lá na escola nova, em maio na verdade, já com o trabalho em andamento, e foi indo até a metade do ano, e estudando com esse grupo. Na metade do ano, surgiu a partir de um texto chamado planejamento participativo no ensino médio... desse texto é que a gente começou a fomentar. Daí o FG, que sempre se identificou com essa área também, de conteúdo, da questão da disciplina, aí a gente foi indo, com o SP, também, então na verdade foi mais no segundo semestre de 2000 que a gente começou, ainda tenho um monte de fotos dos trabalhos. (Professor B).

Destaca-se na fala desse professor, o momento que, segundo ele, deu início à sua maneira atual de atuar pedagogicamente. No nosso entendimento, para além da qualificação que a participação em grupos de estudos pode proporcionar a seus participantes, ressalta-se a importância do envolvimento de várias pessoas em torno de um objetivo comum, como mostra o relato. Os subsídios trazidos pelos professores universitários nessa situação podem ser considerados de fundamental importância, pois facilitaram a imersão no tema pelo professor aqui investigado, bem como ofereceu "ideias" para materializar sua prática pedagógica numa outra perspectiva.

No caso específico dos professores sujeitos desta pesquisa, a busca e a materialização de uma prática inovadora guardam vínculos estreitos com a participação em grupos de estudos. Todos os professores investigados nesta pesquisa fizeram parte, e alguns ainda fazem, de grupos de estudos sobre a área de atuação. Está claro que, para eles, um grupo de estudos, focado para as dificuldades pedagógicas do dia-dia, onde se relata e se ouve experiências, onde se discute e se busca, em conjunto, outras possibilidades para a prática pedagógica, se constitui numa excelente ferramenta de apoio e até de motivação para a mudança pedagógica, como relata o professor A:

Claro que esses encontros eu acho que seriam ricos para a gente continuar fazendo, esse grupo de estudos, que eu não vejo outra saída para a Educação Física; não um curso de pós-graduação, uma especialização... talvez, se tivesse uma discussão assim, a partir da prática.

I I. É professor do curso de graduação em EF da Unijuí. Produz interessantes reflexões acerca do planejamento curricular e em relação a maneiras diferenciadas de se abordar o esporte na EF escolar. Os professores sujeitos desta pesquisa não apenas conheceram sua teoria, mas principalmente vivenciaram a abordagem da Educação Física embebida por essa teoria, na medida em que foram seus alunos de graduação e pós-graduação.

12. Professor Doutor docente do Programa de Pós-Graduação em Educação nas Ciências da Unijuí. Entre outras pesquisas desenvolvidas, destaca-se o projeto de pesquisa que desenvolve em conjunto com outro pesquisador e com outras instituições nacionais e estrangeiras: "Educação Física e Cultura Escolar: entre práticas inovadoras e o abandono do trabalho docente". 
Assim como a participação em um grupo de estudos pode ser considerado um elemento importante na busca pela inovação de uma prática pedagógica, a ausência de um coletivo para compartilhar as mais variadas questões do cotidiano profissional também acaba por constituir um dos principais entraves ao avanço da prática pedagógica. É disso que se ressentem os professores B e C:

Na verdade, eu quero que alguém venha e diga ou sugira acerca de meu trabalho, mas por ser uma coisa nova, e pelo fato de o pessoal gostar, a gente acaba fazendo dessa forma e vai indo, não tem um colega para trocar isso num grupo, a escola aceita, tudo bem, só que você não tem parâmetros, a coisa está tão parada que o que você fizer tá bom, e o pessoal não tem argumentos para te criticar, na verdade alguns ficam até assustados quando nas reuniões você se empolga e apresenta e argumenta em favor daquele trabalho. (Professor B).

Tem que estar se atualizando, estudando, buscando os mais diferentes autores, analisar esses autores e também tu teres com quem trocar, com quem conversar sobre isso, isso é muito importante. (Professor C).

Quanto a esta necessidade de compartilhar saberes, dúvidas, incertezas e soluções, os relatos dos professores acima escancaram a solidão que acompanha os professores de Educação Física e os professores em geral, denominados como "combatentes solitários" (PERRENOUD, 200 I). Na perspectiva de Perrenoud (200 I , p. I64),

O saber dos professores é pouco compartilhado, eles não têm uma linguagem comum para falar da tipologia de alunos ou de erros, do seu modo de organização do tempo ou do espaço, de suas reações à desordem, de sua angustia nos conflitos, de suas estratégias para enfrentar o imprevisto, do tempo que passa, da depressão e da dúvida. É cada um por si não só na prática, mas - e isso é apenas meio lógico - também na teoria de sua prática. Se não há "palavras para dizer", cada um se fecha em sua experiência. Não quer dizer que não constrói nenhum saber, mas que esses saberes não são socializados, não são comparados com outros, não se enriquecem com a história dos outros.

Sensíveis a isso foi que nos propomos a utilizar a técnica do grupo focal. À intenção de colher informações para a pesquisa somava-se a oportunidade oferecida aos professores de debaterem entre si, já que são professores com um perfil semelhante e todos tinham (têm) muito a contribuir com o tema. Isso se comprovou de fato. Na primeira reunião do grupo focal, após alguns primeiros minutos de adequação e ansiedade, se iniciou um debate com os professores se mostrando dispostos a falar abertamente sobre suas experiências pedagógicas.

Na concepção de Nóvoa (200 I ), o melhor caminho para aperfeiçoar a prática pedagógica é debater com os colegas. $\mathrm{O}$ autor entende que se manter atualizado sobre novas metodologias de ensino e desenvolver práticas pedagógicas mais eficientes são alguns dos principais desafios da profissão de educador. Ele também afirma que o melhor lugar para aprender a lecionar é a própria escola: 
A produção de práticas educativas eficazes só surge de uma reflexão da experiência pessoal partilhada entre os colegas [...] Digo que nesta área nada se inventa, tudo se recria. $\bigcirc$ resgate de experiências pessoais e coletivas é a única forma de evitar a tentação das modas pedagógicas. Ao mesmo tempo é preciso combater a mera reprodução de práticas de ensino, sem espírito crítico ou esforço de mudança (NÓVOA, 200 I, p. I4).

O mesmo autor ainda acrescenta que existe certa incapacidade para colocar em prática concepções e modelos inovadores. Explica que a adoção de novas práticas pedagógicas requer um equilíbrio com a tradição. A mudança na maneira de ensinar tem de ser feita com consistência e baseada em práticas de várias gerações.

Pela ótica dos professores investigados não é possível pensar, falar ou investigar sobre a mudança pedagógica em Educação Física sem pensar sobre suas relações com a graduação que, no caso específico desses professores, privilegiou conhecimentos filosófico-humanistas, epistemológicos, científicos, para além dos conhecimentos técnicos; a participação, enquanto acadêmicos, em oficinas e projetos coordenados pelo curso de Educação Física, que proporcionaram a experienciação da prática pedagógica; a formação continuada (contínua) que ressaltou a importância da prática reflexiva e do planejamento curricular; e a participação em grupos de estudos acerca da prática pedagógica em Educação Física. Estes elementos foram mencionados por todos os professores entrevistados nesta pesquisa, evidenciando seu caráter fundante de práticas pedagógicas inovadoras.

\section{CONSIDERAÇÕES FINAIS: QUANDO A DIFERENÇA É SER PROFESSOR}

Finalizando esta escrita e ciente de nossas limitações quanto às possibilidades de aprofundamento em algumas questões que poderiam render outras reflexões, tornamos a enfatizar a importância de valorizarmos as micro-estruturas em pesquisas relacionadas a mudanças pedagógicas, ou seja, levar em consideração o que "dizem" os sujeitos que "fazem" a Educação Física Escolar.

A partir da reflexão tecida em torno do que relataram os professores sujeitos desta pesquisa, entendemos que a trajetória da prática pedagógica do professor de Educação Física está fortemente ligada à sua constituição profissional. Esta pesquisa, porém, evidencia que isso não é suficiente, pois, mesmo "conscientes" desse vínculo, não produzem-se facilmente novas práticas pedagógicas.

Na perspectiva dos sujeitos-participantes desta pesquisa, o fato de a formação inicial ter oportunizado conhecimentos filosófico-humanistas e pontos de experimentação do fazer pedagógico (projetos, oficinas), para além dos conhecimentos técnico-científicos, foi fundamental para a constituiçã̃o de suas práticas. Alertamos, porém, para a necessidade de estudos que levem em consideração outras variáveis no tempo-espaço de formaçãa do professor, pois o fato de a formação inicial privilegiar os 
pontos descritos acima, não garante que o futuro professor será fiel à linha pedagógica trabalhada na instituição onde cursou sua graduação. Dessa forma, entendemos que os elementos reconhecidos pelos professores sujeitos deste estudo como fundamentais para a constituição de suas práticas pedagógicas, e analisados neste estudo, podem ser tomados como ponto de partida para estudos futuros acerca de práticas inovadoras em Educação Física escolar. Algo que, obviamente, não pode desconsiderar a necessidade de um maior aprofundamento acerca do campo de intervenção, em especial, o entorno que constitui a denominada "cultura escolar".

Os casos estudados ilustram possibilidades efetivas de uma nova configuração para a EF escolar, porém não são generalizáveis ao modo de um receituário. Trazem-nos de qualquer forma o alento de que uma outra EF é possível, cabendo aos seus atores configurá-las em consonância com suas crenças e seus contextos de intervenção.

Essaying the "novel" in the School Physical Education: the perspective of the actors

ABSTRACT: The paper is a result of a research with teachers who accomplish 'novel' pedagogic practices in the school physical education. It is searched and analyzed the elements that were and are important, in the teachers' view, to support those pedagogic practices. The reports from investigated teachers and the subsequent analysis of the elements pointed out by them, in one side, reinforce the idea that the comprehension of the totality of that phenomena could not be obtained without examining the complex network of relations among the internal and external school determinants; on the other side, neither it is possible to approach the question without considering the professional trajectory of the 'innovator' teacher.

KEYWORDS: Pedagogic practice; professional studies; physical education in the school; school.

\section{Ensayando el "nuevo" en la Educación Física Escolar: la perspectiva de sus actores}

RESUMEN: Esto artículo resulta de una investigación con maestros que realizan prácticas pedagógicas "innovadoras" en la educación física escolar. Se busca conocer y analizar los elementos que, en la óptica de estos maestros, fueran/están siendo importantes para la realización y suporte de estas prácticas. Las narraciones de los maestros investigados y el análisis subsecuente de los elementos por ellos señalados, por un lado, refuerzan la idea de que la comprensión de la totalidad de este fenómeno no puede sir efectuada sin examinar la complexa red de relaciones de determinantes internos y externos de la escuela; por otro, tampoco es posible abordar el problema sin considerar el recorrido profesional de lo maestro "innovador".

PALABRAS-CLAVES: Práctica pedagógica; estudios profesionales; educación física en la escuela; escuela. 


\section{REFERÊNCIAS}

BETTI, M. Sobre teoria e prática: manifesto pela redescoberta da educação física. Revista Digital. Buenos Aires, ano 10, n. 90, dez. 2005. Disponível em: < http://www.efdeportes. com/>. Acesso em: 17 jan. 2007.

. Educação física escolar: do idealismo à pesquisa-ação. 2002. 336 f. tese (Livre Docência em Métodos e Técnicas de Pesquisa em Educação Física e Motricidade Humana) - Faculdade de Ciências, Universidade Estadual Paulista, Bauru, 2003.

BRACHT, Valter (Org.). Pesquisa em ação: educação física na escola. 2. ed. ljuí: Ed. Unijuí, 2005.

FENSTERSEIFER, P. E.; GONZÁLEZ, F. J. Educação Física e Cultura Escolar: a constituição das disposições que operam na atuação docente. In: Seminário Internacional sobre Práticas Inovadoras e Desinvestimento / Abandono pedagógico na Educação Física escolar na UFES (Vitória - ES). 27-29 de agosto de 2008.

IMBERNÓN, F. Formação docente e profissional: formar-se para a mudança e a incerteza. 6. ed. São Paulo: Cortez, 2006.

NÓVOA, A. Os professores e sua formação. 2. ed. Portugal: Dom Quixote, 1995.

. O passado e o presente dos professores. In: NÓvOA, A. (Org.). Profissão professor. Portugal: Porto, 1999. p. 13-34.

. Professor se forma na escola. Revista Nova Escola, São Paulo, n. 142, v. I6, p. I315, maio de 2001 .

PERRENOUD, P. Ensinar: agir na urgência, decidir na incerteza. 2. ed. Porto Alegre: Artmed, 2001 .

. A prática reflexiva no ofício do professor: profissionalização e razão pedagógica. Porto Alegre: Artmed, 2002.

PIMENTA, S. G.; GHEDIN, E. (Orgs.). Professor reflexivo no Brasil: gênese e crítica de um conceito. São Paulo: Cortez, 2002.

SACRISTÁN, J. G. Consciência e ação sobre a prática como libertação profissional dos professores. In: NÓVOA, A. (Org.). Profissão professor. Portugal: Porto, 1999. p. 82-II3.

SANTINI, J.; MOLINA NETO, V. A síndrome do esgotamento profissional em professores de educação física: um estudo na rede municipal de ensino de Porto Alegre. Revista Brasileira de Educação Física, São Paulo, v. 19, n. 3, p. 209-222, jul./set. 2005.

TARDIF, Maurice. Saberes Docentes e Formação Profissional. Petrópolis: Vozes, 2002. 
Recebido: 08 jun. 2010 Aprovado: 29 set. 2010

Endereço para correspondência: Marlon André da Silva Rua Europa, 212 Altos - Centro Canoas - RS CEP: $92010-180$ 